\title{
KAITINAMOJO TABAKO POVEIKIS SVEIKATAI BEI ŠIRDIES IR KRAUJAGYSLIŲ SISTEMAI
}

\author{
Pranas Šerpytis ${ }^{1,2,3}$, Audrẻ Alonderytė ${ }^{1}$, Robertas Stasys Samalavičius ${ }^{1,2}$, Robertas Badaras ${ }^{1,3}$ \\ ${ }^{1}$ Vilniaus universiteto Medicinos fakultetas, ${ }^{2}$ Vilniaus universiteto ligonine Santaros klinikos, \\ ${ }^{3}$ Respublikiné Vilniaus universitetine ligonine
}

Raktažodžiai: tabakas, rūkymas, kaitinamasis tabakas, kaitinamojo tabako gaminiai, širdies ir kraujagyslių sistema.

\section{Santrauka}

Neigiama rūkymo įtaka sveikatai ne kartą buvo aprašyta ịvairiuose tyrimuose. Rūkymas yra viena pagrindinių išvengiamos mirties priežasčių, todèl vis didesnis dèmesys skiriamas jo modifikavimui. Atsižvelgiant ị rūkymo žalą, siūloma įprastines cigaretes keisti mažiau kenksmingomis. Viena iš siūlomų alternatyvų - kaitinamojo tabako įrenginiai, kurie kaitina tabaką žemesnejje temperatūroje [1], todèl kinta kenksmingų medžiagų koncentracija ir cheminių medžiagų sudètis. Šio tyrimo tikslas - atlikti ne vẻlesnių nei 5 metų mokslinių šaltinių, nagrinejjančių kaitinamojo tabako poveikị sveikatai bei širdies ir kraujagyslių sistemai, analizę. Atrinktos ir išanalizuotos 24 publikacijos. Kaitinamojo tabako aerozolyje yra 50-90 proc. mažiau kenksmingu ir potencialiai kenksmingų medžiagų [2]. Mažesnèje temperatūroje susidaro mažesnis anglies monoksido kiekis, o karboksihemoglobino koncentracija kraujyje sumažèja perpus [3]. Biologiniai žymenys, reaguojantys i kenksmingas ir potencialiai kenksmingas medžiagas, kurios išsiskiria ịprastinių cigarečių rūkymo metu, ženkliai sumažeja, pakeitus jas kaitinamuoju tabaku [4]. Nikotino kiekis tiek išsiskiriančiuose dūmuose, tiek žmogaus organizme, vartojant kaitinamojo tabako gaminius ar ịprastines cigaretes, yra panašus [5]. Rūkymas daro itaką ne tik rūkančiam asmeniui, bet ir aplinkiniams. Pasyvusis rūkymas didina riziką sirgti širdies ir kraujagyslių ligomis. Naudojant kaitinamojo tabako įrenginius, galima sumažinti potencialiai kenksmingų išsiskiriančių medžiagų kiekị [6]. Kaitinamojo tabako alternatyva galètų būti svarstoma kaip mažiau kenksmingas sveikatai rūkymo būdas asmenims, kuriems sunku mesti rūkyti ịprastines cigaretes [7].

\section{Ivadas}

Tabako vartojimas yra viena pagrindinių išvengiamos mirties priežasčių, kasmet nusinešanti daugiau nei 6 milijonus gyvybių visame pasaulyje. Trečdalį šių mirčių sudaro širdies ir kraujagyslių ligos (ŠKL) [8]. Rūkymas, skirtingai nei kiti ŠKL rizikos veiksniai, tokie kaip arterinè hipertenzija, dislipidemija ar diabetas, yra modifikuojamas ir galima išvengti jo sukeliamos žalos kardiovaskulinei sistemai [9]. Kasdien surūkant po vieną cigaretę, tikimybė susirgti koronarine širdies liga (KŠL) padidèja 40-50 proc., lyginant su tais asmenimis, kurie surūko po 20 cigarečių kasdien. Tai reiškia, jog net ir nedidelis surūkomų cigarečių kiekis nemažina susirgimo KŠL rizikos. Ir aktyvus, ir pasyvus rūkymas skatina endotelio disfunkcijos atsiradimą, todẻl išsivysto aterosklerozė ir susergama KŠL [8]. Taip yra todèl, jog širdies ir kraujagyslių sistema yra labai jautri tabako dūmams ir su jais išsiskiriančioms kenksmingoms medžiagoms [9]. Cigarečių dūmuose yra $>7000$ cheminių medžiagų, įskaitant nikotiną, dervas, anglies monoksidą $(\mathrm{CO})$, kurios veikia širdies ir kraujagyslių sistemą, didina širdies susitraukimų dažnį, miokardo kontraktiliškumą, skatina uždegimines reakcijas, endotelio disfunkciją, trombų formavimąsi ir mažina didelio tankio lipoproteinų kiekị kraujyje [10].

Neseniai rinkoje pristatytos kaitinamojo tabako sistemos, kurios galètų pakeisti ịprastines cigaretes. Šie įrenginiai pasižymi mažesniu kenksmingumu sveikatai dèl ypatingo veikimo mechanizmo [1]. Saugesnè kaitinamojo tabako alternatyva, iš kurios būtų galima gauti nikotino ir išsiskirtu mažiau dervų ar CO, buvo pasiūlyta 1988 metais, o kaitinamojo tabako ịrenginys IQOS pristatytas 2014 metais Italijoje, Japonijoje ir Šveicarijoje [6]. 2020 metais JAV maisto ir vaistų administracija (FDA) IQOS pripažino modifikuotos rizikos tabako produktu. Tai pirmasis tabako gaminys, kuri galima traktuoti kaip išskiriantị mažiau kenksmingų medžiagų, todèl šis produktas gali prisidèti prie visuomenès sveikatos gerinimo [11]. 
Pastaruoju metu vis daugiau dèmesio skiriama modifikuojamų rizikos veiksnių prevencijai. Amerikos širdies asociacijos 2014 m. pranešime teigiama, jog ši alternatyva turètų būti svarstytina pacientams, kuriems kiti būdai, padedantys mesti rūkyti (švietimas ir medikamentinis gydymas), yra neveiksmingi.

Tyrimo tikslas - atlikti ne vèlesnių nei 5 metų mokslinių šaltinių, nagrinejjančių kaitinamojo tabako poveikị sveikatai bei širdies ir kraujagyslių sistemai, analizę.

\section{Tyrimo objektas ir metodika}

Duomenys buvo renkami PubMed duomenų bazèje. Analizei naudoti visateksčiai straipsniai, kuomet jų pavadinimas, santrauka ar raktažodžiai atitiko apžvalgos tikslą. Analizuotos tik anglų kalba skelbtos publikacijos, pasirodžiusios ne vèliau nei prieš 5 metus. Analizei atrinktos ir išanalizuotos 24 publikacijos.

\section{Tyrimo rezultatai}

Pats geriausias sprendimas rūkančiam asmeniui - mesti rūkyti. Praktika parodè, kad daugelis negali atsisakyti rūkymo, o dalis metusiujų vèl grįžta prie šio žalingo ịpročio. Būtent dèl šios priežasties turètų būti ieškoma alternatyvų asmenims, kurie negali mesti rūkyti. Pastaruoju metu siūlomos įvairios strategijos, kuriami alternatyvūs įrenginiai, kurių žala sveikatai nėra tokia didelè, kaip tradicinis cigarečių rūkymas. Tabako sukeliamos žalos mažinimas apima įvairių sveikatos rodiklių, kuriuos paveikia rūkymas, mažinimą, prilygstantị metimui rūkyti. Tobulëjant technologijoms, sukurti ịvairūs preparatai ar įrenginiai, kurių pagalba galima gauti nikotino. Vienas iš jų - kaitinamojo tabako sistemos [12].

Kaip ir ịprastinès cigaretès (IC), kaitinamojo tabako gaminiai pagaminti iš tikro tabako, tačiau jiems pagaminti sunaudojamas mažesnis jo kiekis. Dèl kitokio veikimo mechanizmo ir žemos kaitinimo temperatūros, kaitinamojo tabako įrenginiai išskiria mažiau kenksmingų medžiagų [13]. Kenksmingų medžiagų koncentracija ir cheminių medžiagų sudètis priklauso nuo degimo temperatūros cigaretès viduje. Rūkant İC degimas pasiekia $700-950{ }^{\circ} \mathrm{C}$, o naudojant kaitinamaji elementą, ši temperatūra neviršija $350{ }^{\circ} \mathrm{C}$, todèl mažèja kenksmingų ir potencialiai kenksmingų medžiagu išsiskyrimo kiekis [1].

Tabako kompanijų atliktuose tyrimuose teigiama, jog kaitinamojo tabako produktų (KTP) išskiriamame aerozolyje yra 90-95 proc. mažiau kenksmingų medžiagų $[14,15]$. Atliktuose nepriklausomuose tyrimuose šie duomenys buvo iš dalies patvirtinti. X. Li ir kt. atliktame tyrime nustatyta, jog IQOS išskiria $>90$ proc. mažesnę kenksmingų ir potencialiai kenksmingų medžiagų kiekį, o karbonilo, amoniako ir N-nitrozoanabastino 50-80 proc. mažesnị kieki [16]. K.
Farsalinos ir kt. atliktame tyrime buvo nustatyta, jog rūkant IQOS, išsiskiria ženkliai mažesnis kiekis karbonilo, nei rūkant IC , tačiau šis kiekis buvo didesnis, lyginant su elektroninèmis cigaretemis [17]. N. Mallock ir kt. studija irode, jog IQOS, lyginant su IC, išskiria mažiau aldehidų (apie 80-95 proc.) ir lakiujjų organinių darinių (apie 97-99 proc.) [1]. Šie tyrimai iš dalies pagrindžia tabako kompanijų atliktus tyrimus ir parodo, jog kaitinamojo tabako aerozolyje yra mažesnis kenksmingų medžiagų kiekis [18].

CO labiausiai kenkia plaučiams bei širdies ir kraujagyslių sistemai [19]. Palyginę išsiskirianti jo kiekị İC ir KTP, $\mathrm{K}$. Bekki ir kt. tyrejai nustate, jog CO koncentracija KTP yra beveik 100 kartų mažesné, negu IC. Manoma, jog tokia žema koncentracija išsiskiriančiame aerozolyje gali būti dèl kaitinamojo mechanizmo ir žemos degimo temperatūros [20]. Reikètų atkreipti dèmesị ị tai, jog asmenims, pakeitusiems IC ị KTP, karboksihemoglobino kiekis kraujyje per 5 dienas sumažèjo 50 proc. nuo pradinio. Šis pokytis turèjo teigiamą efektą, norint sumažinti norą surūkyti dar vieną cigaretę, tačiau apklausus pacientus, buvo pastebėta, jog jie nejaučia tokio pasitenkinimo, kaip rūkydami İC. Kita vertus, rūkantieji, pradėję naudoti KTP, suvartojo jų 20 proc. mažiau, nei İC [3]. Lenkijoje viešosios nuomonès tyrimų instituto (CBOS) surengtos apklausos, kurioje dalyvavo 1000 suaugusiujų, duomenys parode, jog 50 proc. asmenų, pradejjusių vartoti KTP, metė rūkyti [2]. Lyginant su IC, nikotino kiekis kaitinamojo tabako dūmuose sudaro 70-80 proc., o lyginant su elektroninemis cigaretemis, didesnis jo kiekis buvo KTP. Pagal farmakokinetines savybes nikotinas, išsiskiriantis iš KTP, pasiekia panašią koncentraciją, kaip ir İC žmogaus organizme [18]. Tai svarbu dèl to, jog dèl pakankamos nikotino koncentracijos sumažèja rizika vèl griebtis İC rūkymo [1].

Išsiskiriančios kenksmingos medžiagos rūkant turi poveikị ne tik rūkančio asmens, bet ir aplinkinių sveikatai. Nors pastaruoju metu buvo griežtinami ịstatymai, ribojantys rūkymą viešosiose vietose, tačiau aplinkoje esantys tabako dūmai paveikia net 40 proc. vaikų ir 35 proc. nerūkančių suaugusiuju visame pasaulyje. Pastebėtas ryšys tarp moterų, gyvenančių kartu su rūkančiais vyrais ir padidejjusios KŠL sergamumo ir mirtingumo rizikos. Tyrimų duomenimis, su rūkančiaisiais gyvenančių nerūkančių asmenų rizika mirti nuo KŠL padideja 30 procentų [21]. Atliktuose tyrimuose pastebèta, jog naudojant kaitinamojo tabako gaminius, išsiskiriančių kenksmingų ir potencialiai kenksmingų medžiagų kiekis yra mažesnis, nei İC, o aplinkiniams pasyvus rūkymas mažiau kenksmingas [6]. Nors KTP kenksmingų medžiagų išsiskiria mažiau, tai nereiškia, jog jų nèra [14]. T.Tabuchi ir kt. atliktame tyrime vertintas KTP pasyvaus rūkymo poveikis. Tyrimo metu nustatyta, jog 37 proc. asmenu pasireiške bent 1 simptomas, o pasyvusis rūkymas labiausiai 
paveikè nerūkančiuosius. Dažniausiai įvardinti simptomai buvo prasta savijauta ( 25 proc.), akių skausmas (22,3 proc.), gerklès perštėjimas (20,6 proc.) [22].

Atliktuose tyrimuose nustatyta, jog pakeitus İC ị KTP, stebimas ryškus tam tikrų biologinių žymenų, padidejjančių dèl atsako ị išsiskiriančias kenksmingas ir potencialiai kenksmingas medžiagas, kiekio sumažèjimas [4]. Buvo vertinami biologiniai žymenys, atspindintys lipidų metabolizmą (mažo tankio lipoproteinų cholesterolis (MTL), trigliceridai), uždegiminius rodiklius (fibrinogenas, C-reaktyvus baltymas, baltujų kraujo kūnelių skaičius), oksidacinị stresą (8-epiprostaglandinas F2, malondialdehidas, oksiduotas MTL, gliutationo peroksidazė ir kt.) bei jų kiekio priklausomybė nuo tabako vartojimo. Gauti rezultatai parode, jog rūkant IC šie žymenys smarkiai padidejja, todèl didejja rizika sirgti kardiovaskulinèmis ligomis. Pakeitus İC į KTP, šiu žymenų koncentracija ženkliai sumažèja po 5 dienų $[3,23]$.

Dauguma studijų yra santykinai mažos trukmès, todèl sunku pasakyti, ar KTP poveikis pakankamas sumažinti susirgimo ịvairiomis ligomis riziką $[12,24]$, tačiau svarbu atkreipti dèmesi $i$ atliktus tyrimus, kuriuose stebimas aiškus biožymenų ir kenksmingų medžiagų išsiskyrimo sumažèjimas. Šie rezultatai parodo, jog šiuo atžvilgiu naudinga keisti ịprastinių cigarečių rūkymą kitomis alternatyvomis, tokiomis kaip kaitinamojo tabako gaminiai [12]. Paminètina, jog FDA 2020 metais patvirtino IQOS kaip modifikuotos rizikos tabako gaminị, išskiriantị mažiau kenksmingų ir potencialiai kenksmingų medžiagų [11]. Ši alternatyva galètų būti tinkama tik tiems asmenims, kuriems sunku mesti rūkyti, pasiūlant jiems mažiau kenksmingus rūkymo būdus [7], nors geriausias sprendimas yra atsisakyti šio žalingo ịpročio [24].

\section{Išvados}

1. Kaitinamojo tabako gaminiai išskiria mažiau kenksmingų ir potencialiai kenksmingų medžiagų, lyginant su iprastinèmis cigaretemis.

2. Vartojant kaitinamojo tabako gaminius, po 5 dienų karboksihemoglobino koncentracija kraujyje sumažeja 50 proc., lyginant su pradine.

3. Vartojant kaitinamojo tabako gaminius ir iprastines cigaretes, nikotino kiekis išsiskiriančiuose dūmuose ir žmogaus organizme yra panašus.

4. Biožymenys, reaguojantys ị kenksmingas ir potencialiai kenksmingas medžiagas, kurios išsiskiria ịprastinių cigarečių rūkymo metu, ženkliai sumažèja, pakeitus jas kaitinamuoju tabaku.

5. Pasyvusis rūkymas didina riziką sirgti širdies ir kraujagyslių ligomis. Naudojant kaitinamojo tabako ịrenginius, galima sumažinti potencialiai kenksmingų išsiskiriančių medžiagų kieki.
6. Kaitinamojo tabako alternatyva galètų būti svarstoma kaip mažiau sveikatai kenksmingas rūkymo būdas asmenims, kuriems sunku mesti rūkyti ịprastines cigaretes.

\section{Literatūra}

1. Mallock N, Pieper E, Hutzler C, Henkler-Stephani F, Luch A. Heated tobacco products: a review of current knowledge and initial assessments. Front Public Health 2019;10(7):287. https://doi.org/10.3389/fpubh.2019.00287

2. Górski P. E-cigarettes or heat-not-burn tobacco products - advantages or disadvantages for the lungs of smokers. Adv Respir Med 2019;87(2):123-134.

https://doi.org/10.5603/ARM.2019.0020

3. Szymański FM, Piotr Kuna P, Płatek AE, Kowalik R, Gotlib J, Filipiak KJ. Heat-not-burn tobacco products and patient health: Expert Group opinion; Heart and Cardiovascular diseases 2019;16(2):135-142.

4. Lüdicke F, Ansari SM, Lama N, Blanc N, Bosilkovska M, Donelli A, et al. Effects of switching to a heat-not-burn tobacco product on biologically relevant biomarkers to assess a candidate modified risk tobacco product: a randomized trial. Cancer Epidemiol Biomarkers Prev 2019;28(11):1934-43.

https://doi.org/10.1158/1055-9965.EPI-18-0915

5. Brossard P, Weitkunat R, Poux V, Lama N, Haziza C, Picavet P, et al. Nicotine pharmacokinetic profiles of the tobacco heating system 2.2, cigarettes and nicotine gum in Japanese smokers. Regul Toxicol Pharmacol 2017;89:193-9.

https://doi.org/10.1016/j.yrtph.2017.07.032

6. Simonavicius E, McNeill A, Shahab L, Brose LS. Heat-not-burn tobacco products: a systematic literature review. Tob Control 2019;28(5):582-94.

https://doi.org/10.1136/tobaccocontrol-2018-054419

7. Lachenmeier DW, Monakhova YB, Rehm J, Kuballa T, Straub I. Occurrence of carcinogenic aldehydes in alcoholic beverages from Asia. Int J Alcohol Drug Res 2013;2(2):31-6. https://doi.org/10.7895/ijadr.v2i2.88

8. Kondo T, Nakano Y, Adachi S, Murohara T. Effects of tobacco smoking on cardiovascular disease. Circ J 2019;83(10):1980-5. https://doi.org/10.1253/circj.CJ-19-0323

9. Conklin DJ, Schick S, Blaha MJ, Carll A, DeFilippis A, Ganz P, et al. Cardiovascular injury induced by tobacco products: assessment of risk factors and biomarkers of harm. A tobacco centers of regulatory science compilation. Am J Physiol-Heart Circ Physiol. 2019;316(4):H801-27. https://doi.org/10.1152/ajpheart.00591.2018

10. Slob W, Soeteman-Hernández LG, Bil W, Staal YCM, Stephens WE, Talhout R. A method for comparing the impact on carcinogenicity of tobacco products: a case study on heated tobacco versus cigarettes. Risk Anal 2020;40(7)1355-1366. https://doi.org/10.1111/risa.13482

11. FDA authorizes marketing of IQOS tobacco heating system 
with 'Reduced Exposure' information. ET HealthWorld 2020.

12. Bosilkovska M, Tran CT, de La Bourdonnaye G, Taranu B, Benzimra M, Haziza C. Exposure to harmful and potentially harmful constituents decreased in smokers switching to carbonheated tobacco product. Toxicol Lett 2020;330:30-40.

https://doi.org/10.1016/j.toxlet.2020.04.013

13. Pacitto A, Stabile L, Scungio M, Rizza V, Buonanno G. Characterization of airborne particles emitted by an electrically heated tobacco smoking system. Environ Pollut 2018;240:248-54. https://doi.org/10.1016/j.envpol.2018.04.137

14. Jaccard G, Tafin Djoko D, Moennikes O, Jeannet C, Kondylis A, Belushkin M. Comparative assessment of HPHC yields in the tobacco heating system THS2.2 and commercial cigarettes. Regul Toxicol Pharmacol 2017;90:1-8.

https://doi.org/10.1016/j.yrtph.2017.08.006

15. Pratte P, Cosandey S, Goujon Ginglinger C. Investigation of solid particles in the mainstream aerosol of the tobacco heating system THS2.2 and mainstream smoke of a 3R4F reference cigarette. Hum Exp Toxicol 2017;36(11):1115-20. https://doi.org/10.1177/0960327116681653

16. Li X, Luo Y, Jiang X, Zhang H, Zhu F, Hu S, et al. Chemical analysis and simulated pyrolysis of tobacco heating system 2.2 compared to conventional cigarettes. Nicotine Tob Res 2019;21(1):111-8. https://doi.org/10.1093/ntr/nty005

17. Farsalinos KE, Yannovits N, Sarri T, Voudris V, Poulas K, Leischow SJ. Carbonyl emissions from a novel heated tobacco product (IQOS): comparison with an e-cigarette and a tobacco cigarette: Carbonyl emissions in heated tobacco product. Addiction 2018;113(11):2099-106.

https://doi.org/10.1111/add.14365

18. Jankowski M, Brożek G, Lawson J, Skoczyński S, Majek P, Zejda J. New ideas, old problems? Heated tobacco products - a systematic review. Int J Occup Med Environ Health 2019;32(5):595-634.

https://doi.org/10.13075/ijomeh.1896.01433

19. Darville A, Hahn EJ. E-cigarettes and atherosclerotic cardiovascular disease: what clinicians and researchers need to know. Curr Atheroscler Rep 2019;21(5):15. https://doi.org/10.1007/s11883-019-0777-7

20. Bekki K, Inaba Y, Uchiyama S, Kunugita N. Comparison of chemicals in mainstream smoke in heat-not-burn tobacco and combustion cigarettes. J UOEH 2017;39(3):201-7.

https://doi.org/10.7888/juoeh.39.201

21. Argacha JF, Bourdrel T, van de Borne P. Ecology of the cardiovascular system: a focus on air-related environmental factors. Trends Cardiovasc Med 2018;28(2):112-26.

https://doi.org/10.1016/j.tcm.2017.07.013

22. Tabuchi T, Gallus S, Shinozaki T, Nakaya T, Kunugita N, Colwell B. Heat-not-burn tobacco product use in Japan: its prevalence, predictors and perceived symptoms from exposure to secondhand heat-not-burn tobacco aerosol. Tob Control 2018;27(e1):e25-33.

https://doi.org/10.1136/tobaccocontrol-2017-053947

23. Gale N, McEwan M, Eldridge AC, Fearon IM, Sherwood $\mathrm{N}$, Bowen $\mathrm{E}$, et al. Changes in biomarkers of exposure on switching from a conventional cigarette to tobacco heating products: a randomized, controlled study in healthy Japanese subjects. Nicotine Tob Res 2019;21(9):1220-7.

https://doi.org/10.1093/ntr/nty104

24. Başaran R, Güven NM, Eke BC. An overview of iQOS ${ }^{\circledR}$ as a new heat-not-burn tobacco product and its potential effects on human health and the environment. Turk J Pharm Sci 2019;16(3):371-4.

https://doi.org/10.4274/tjps.galenos.2018.79095

\section{HEAT-NOT-BURN TABACCO IMPACT ON HEALTH AND CARDIOVASCULAR SYSTEM}

\section{P. Šerpytis, A. Alonderytė, R.S. Samalavičius, R. Badaras}

Keywords: tobacco, smoking, heat-not-burn, heating tobacco system, cardiovascular system.

Summary

The negative health effects of smoking have been repeatedly described by various researchers. Smoking is one of the major cause of preventable deaths and more attention is paid to its modification. Given the damage it causes, new alternatives are proposed that are not as harmful as regular cigarettes. One of them is heated tobacco products, which heat tobacco at a lower temperature [1]. As a result, the concentration of harmful substances and the composition of chemicals change. Heated tobacco aerosol contains $50-90 \%$ less harmful and potentially harmful substances [2]. In addition to this, lower temperature produce lower levels of carbon monoxide and the levels of carboxyhemoglobin in the blood decreases in half [3]. Biomarkers that respond to harmful and potentially harmful substances released during conventional cigarette smoking are significantly reduced by replacing regular cigarettes with heat-not-burn tobacco [4]. Nicotine levels in both emitted smoke and the human body remain similar with the use of smoking heat-not-burn tobacco products and regular cigarettes [5]. Smoking affects not only the smoker himself, but also those around him. Passive smoking increases the risk of cardiovascular disease, and the use of heat-notburn tobacco can reduce the amount of potentially harmful emissions [6]. An alternative of heated tobacco should be considered for those who are unable to quit and continue to use regular cigarettes, in order to reduce their negative health effects [7].

Correspondence to: pranas.serpytis@santa.lt

Gauta 2020-10-22 